\title{
The Role of Affect in the Mere Exposure Effect: Evidence from Psychophysiological and Individual Differences Approaches
}

\author{
Eddie Harmon-Jones \\ University of Wisconsin-Madison \\ John J. B. Allen \\ University of Arizona
}

senting novel stimuli repeatedly without any reinforcement produces more positive attitudes toward those stimuli. This effect has been termed the mere exposure effect (Zajonc, 1968). It has been found robustly in humans (for a review, see Bornstein, 1989); with stimuli that are presented so briefly that they are not consciously perceived (for a review, see Bornstein, 1992); with abstract, nonrepresentational stimuli and meaningful, social stimuli (Saegert, Swap, \& Zajonc, 1973); in positive and negative contexts (Saegert et al., 1973); in laboratory and field settings (e.g., Moreland \& Zajonc, 1976; Zajonc \& Rajecki, 1969); and in nonhuman animals (for a review, see Hill, 1978).

Authors' Note: We thank Dan Batson, Richard Bootzin, Jack Brehm, Chris Burris, Tamra Pearson d'Estree, Jeff Greenberg, Cindy HarmonJones, Gary Schwartz, Varda Shoham, and Piotr Winkielman for their comments on earlier drafts of this article. We thank Trisha Casanova, Laurie DeLuca, and Tessa Sartain for assisting with the data collection and Mark Bakarich and Jonathan Forster for providing technical assistance. The experiment was run using the DMASTR software developed at Monash University and at the University of Arizona by K. I. Forster and J. C. Forster. This research was supported by a dissertation award from the University of Arizona and by a grant from the McDonnell-Pew Program in Cognitive Neuroscience. Portions of these data were presented at the 36th Annual Meeting of the Society for Psychophysiological Research, October 1996, Vancouver, Canada. Correspondence concerning this article should be addressed to Eddie Harmon-Jones, University of Wisconsin-Madison, Department of Psychology, 1202 West Johnson Street, Madison, WI 53706; e-mail: eharmonj@facstaff.wisc.edu.

PSPB, Vol. 27 No. 7, July $2001889-898$

(C) 2001 by the Society for Personality and Social Psychology, Inc. 


\section{EXPLANATIONS OF THE MERE EXPOSURE EFFECT}

\section{Affective Models}

Several models have been proposed to explain the mere exposure effect. Zajonc (1968) postulated that there might be biological significance to the effect so that a stimulus presented for the first time evokes "an instinctive fear reaction" (p. 19) or an orienting response, and this response habituates with repeated, unreinforced exposure to stimuli (Zajonc, 1998). Other models have also posited that mere exposure influences affective reactions to the stimuli (for reviews, see Bornstein, 1989; Harrison, 1977; Hill, 1978).

However, as Bornstein (1989) pointed out, none of the models has satisfactorily addressed why the effect occurs. He proposed an affective model with principles derived from evolutionary theory. For adults, it may be adaptive to prefer the familiar over the novel. Because novel objects could present a potential threat, organisms that had a fear of the strange and unfamiliar were more likely to survive, reproduce, and pass on genetic material and inherited traits to subsequent generations than organisms that lacked fear of novelty. Preferring the familiar may be an adaptive trait that has evolved in humans and nonhumans (Bowlby, 1958; Bronson, 1968; Hill, 1978). According to this model, unfamiliar as compared with familiar stimuli may be associated with more negative attitudes because of the unfamiliar stimuli's association with potential danger (see Zajonc, Crandall, Kail, \& Swap, 1974, for evidence that familiar stimuli are rated as less harmful than unfamiliar stimuli). ${ }^{1}$

\section{Cognitive Models}

Nonspecific activation model. In contrast to the affective models, recent cognitive models of mere exposure have proposed that affect is not involved in the mere exposure effect. For instance, the nonspecific activation model proposes that brief exposures to stimuli produce memory representations that lack contextual reference. When persons are asked to make judgments and evaluations of these stimuli, they are likely to judge the stimuli as being more likely to possess the stimulus dimension being tested, as long as the stimulus dimension is a plausible characteristic of the stimulus. In one experiment testing this model (Mandler, Nakamura, \& Van Zandt, 1987), participants were asked to judge whether the familiar or novel stimuli were more bright, more dark, more likable, or more dislikable. As predicted, participants judged familiarized stimuli as more bright, dark, and likable than novel stimuli (where all stimuli were black irregular polygons on a white background, with neutral density and red gelatin filters used to lower illumination). In contrast to predictions derived from the nonspecific activation model, however, participants did not judge familiarized stimuli as more dislikable than novel stimuli.

Perceptual fluency/attributional model. Similarly, the perceptual fluency/attributional model proposes that affect is not involved in the mere exposure effect (Bornstein \& D'Agostino, 1992, 1994). The model is based on the nonspecific activation model (Mandler et al., 1987) and other models (e.g., Seamon, Brody, \& Kauff, 1983). It proposes that familiar stimuli are easier to perceive, encode, and process than are unfamiliar stimuli; that is, they have increased perceptual fluency (Jacoby \& Whitehouse, 1989). The model further proposes that when individuals experience perceptual fluency for a stimulus, they are unable to explain that increased perceptual-encoding processes have occurred. Instead, they generate the most reasonable explanation available to explain the experience of perceptual fluency. Situational constraints and available contextual cues will then guide the generation of their explanations for the experience of perceptual fluency. According to this model, mere exposure increases the experience of perceptual fluency for stimuli, and the situational constraints and the contextual cues provided in mere exposure experiments cause persons to misattribute the perceptual fluency to liking or to any stimulus property that persons are asked to rate. This model predicts that familiarized stimuli will be evaluated more negatively if negative evaluations are asked of participants. Thus, according to the nonspecific activation and the perceptual fluency/attribution models, the increased liking that results from mere exposure is not genuine and is only an artifact of the experimental questions that are posed to participants.

Concerns about the cognitive models. However, a few caveats should be considered before accepting the nonspecific activation and perceptual fluency/attributional models of mere exposure. First, recent research by Seamon, McKenna, and Binder (1998) has failed to replicate the effects on brightness and darkness judgments obtained by Mandler et al. (1987). In addition, this same research has found that familiarized stimuli were judged to be more likable and less dislikable than novel stimuli (Seamon et al., 1998), which is a finding opposite to predictions advanced by nonspecific activation and perceptual fluency/attributional models of mere exposure. Similarly, these cognitive models have difficulty explaining past research that shows that familiarized stimuli are evaluated more positively rather than more negatively in experiments in which negative evaluations were assessed (e.g., Seamon et al., 1998; Zajonc, 1968; Zajonc et al., 1974; Zajonc, Markus, \& Wilson, 1974a; Zajonc, Shaver, Tavris, \& Van Kreveld, 1972). 


\section{An Affective-Perceptual Fluency Model}

Other scientists have proposed that perceptual fluency can account for mere exposure effects via an affective mechanism. According to this model, perceptual fluency itself produces feelings of pleasantness and does not produce nonspecific activation that can be misattributed to produce negative evaluations of merely exposed stimuli (Reber, Winkielman, \& Schwartz, 1998; Seamon et al., 1998). According to this model and its supporting research, mere exposure may modulate affective responses by way of perceptual fluency. That is, as the stimuli become more familiarized, they become more perceptually fluent, and this increase in fluency may then increase positive affective responses.

\section{THE PRESENT RESEARCH}

\section{Does Mere Exposure Influence Affective Responses?}

Several affective models propose that mere exposure to a stimulus increases the positive affect or reduces the negative affect toward the stimulus, whereas recent cognitive models propose that affect is not involved in the mere exposure effect. Although recent research suggests that affect is involved in the mere exposure effect, it does not provide unequivocal support for the idea that mere exposure modulates affective responses, because self-reported evaluations of the stimuli may reflect cognitive responses, as the nonspecific activation and perceptual fluency/attribution models would suggest. That is, the self-reported attitudes and judgments may reflect more of a cognitive response than an affective response to the stimulus. Thus, the primary purpose of the present research was to test the hypothesis that mere exposure would influence affective responses using measures other than self-report.

To accomplish this goal, we measured facial electromyographic (EMG) responses to familiarized and unfamiliarized stimuli, because EMG provides sensitive, real-time measures of emotional response. Research assessing facial EMG has reliably demonstrated that activity over the corrugator supercilii muscle region (brow) is increased during negative affective states and decreased during positive affective states and that activity over the zygomaticus major muscle region (cheek) is increased during positive affective states and decreased during negative affective states (Cacioppo, Tassinary, \& Fridlund, 1990; Dimberg, 1990; Lang, Bradley, \& Cuthbert, 1997). We predicted that familiarized stimuli would evoke greater zygomatic muscle region activity and/or lesser corrugator muscle region activity than novel stimuli. This hypothesis follows from several explanations of mere exposure but has never been tested.
We also tested the hypothesis that familiarity would affect motivational responses by assessing frontal cortical activity. Past research has suggested that the frontal regions of the brain mediate approach and withdrawal motivation, with heightened approach motivation being reflected in relatively greater left than right frontal activity and heightened withdrawal motivation being reflected in relatively greater right than left frontal activity (Davidson, 1995). Thus, if familiar stimuli increase approach motivation and/or novel stimuli increase withdrawal motivation, then familiar stimuli should increase left frontal cortical activity and/or novel stimuli should increase right frontal cortical activity.

\section{Do Individual Differences Moderate the Mere Exposure Effect?}

A second purpose of the present research was to assess whether individual differences in affective traits would moderate reactions to merely exposed stimuli. If affect is influenced by mere exposure, then individual differences in affective traits should influence the strength of the mere exposure effect. Although the mere exposure effect has been demonstrated in more than 200 experiments, the influence of individual differences in susceptibility to it has been tested only eight times. Of the individual difference variables examined, only anxiety (Schick, McGlynn, \& Woolam, 1972), boredom proneness (Bornstein, Kale, \& Cornell, 1990), and toleranceintolerance of ambiguity (Crandall, 1968) have been found to relate to the mere exposure effect. Persons with high anxiety, low boredom proneness, and intolerance of ambiguity prefer the familiarized to the unfamiliarized more than do their counterparts on these individual difference variables.

If the enhanced positive evaluative responses to the familiar occur as a result of affective processes, then persons with greater negative affective styles or lesser positive affective styles may show more positive evaluations and positive affect for the familiar. Thus, persons with higher levels of negative affect and persons with lower levels of positive affect are predicted to evaluate the familiar more positively than the unfamiliar and evidence more zygomatic activity and less corrugator activity to the familiar than to the unfamiliar.

In addition, we hypothesized that persons with greater withdrawal tendencies or with lower approach tendencies would be especially likely to respond with increased positive evaluations and positive affect to mere exposure. We assessed individual differences in approach and withdrawal motivational tendencies by recording frontal brain activity. Research has found that individual differences in approach and withdrawal tendencies relate to individual differences in resting asymmetries in the frontal brain regions (Harmon-Jones \& 
Allen, 1997; Sutton \& Davidson, 1997). Other research has shown that the individual differences in resting asymmetrical frontal brain activity predict affective responses. For instance, individuals with greater right than left frontal cortical activity at baseline reported more global negative affect to negative emotionevoking film clips than did individuals with greater left than right frontal activity (Tomarken, Davidson, \& Henriques, 1990). Research has also found that asymmetries in frontal activation have high test-retest stability (Tomarken, Davidson, Wheeler, \& Kinney, 1992), suggesting that the asymmetry in large part reflects a trait.

\section{Overview of Present Experiment}

To test these hypotheses, we designed an experiment using procedures similar to those used in past mere exposure research (Bornstein, Leone, \& Galley, 1987; Kunst-Wilson \& Zajonc, 1980) that were most likely to produce a robust mere exposure effect (for a review, see Bornstein, 1989). In the experiment, persons were repeatedly exposed to photographs of 10 women. Then, they viewed these 10 familiarized women and 10 unfamiliarized women while their facial EMG and electroencephalogram (EEG) responses were recorded. After viewing each photograph, they reported how much they liked the woman displayed in the photograph.

We predicted that mere exposure would increase zygomatic region muscle activity and/or decrease corrugator muscle region activity and affect asymmetrical frontal cortical activity. Moreover, we predicted that the mere exposure effect would be moderated by individual differences in positive affect, negative affect, and relative left frontal brain activity, which has been found to relate to the expression of approach motivation. That is, individuals with low positive affect, high negative affect, and relatively less left frontal brain activity were predicted to evidence a stronger mere exposure effect.

\section{METHOD}

\section{Participants}

Thirty-seven women who were strongly right-handed (by self-report) (Chapman \& Chapman, 1987) participated in the experiment in exchange for credit toward their introductory psychology grades. Only righthanded women were used because the laterality of cerebral function may differ for right- as compared with lefthanded individuals. Four participants were excluded from the analyses: 2 because the computer acquiring the physiological data malfunctioned, 1 because she did not follow instructions in rating the pictures, and 1 because she did not view the pictures the entire time they were displayed on the monitor. Additional data were lost, cre- ating differences in degrees of freedom in various analyses. These reflect loss of psychophysiological data due to high impedances (two due to high impedances at EMG sites and three due to high impedances at EEG sites).

\section{Procedure}

Participants were informed that the 2-hour session would consist of two experiments, one that assessed the relation between brainwaves and personality characteristics and one that assessed brainwaves during the processing of visual information. After participants provided informed consent, electrodes were affixed to their face and scalp to assess facial EMG and EEG, respectively. Participants were then seated alone in a dimly lit soundattenuated room and given the Positive and Negative Affect Schedule-State Version (Watson, Clark, \& Tellegen, 1988) and the Social Anxiety and Distress Scale (Watson \& Friend, 1969). Once the participant had completed the questionnaires, resting EEG and EMG were recorded for 4 minutes, as in previous research (Harmon-Jones \& Allen, 1998; Tomarken et al., 1992).

Participants then viewed a series of pictures of women's faces. Photographs of 10 different women's faces taken from a high school yearbook (subtending vertical and horizontal visual angles of $4.72^{\circ}$ and $3.37^{\circ}$, respectively) were presented five times in a heterogeneous presentation sequence by a computer monitor (exposure duration was 98 milliseconds; intertrial interval was 2,000 milliseconds). Two sets (A and B) of 10 photographs that had been rated by other participants as equally likable were used. For half of the participants, Set A was familiar and Set B was unfamiliar; for the other half, this was reversed.

Five minutes after viewing these photos, participants viewed the 10 previously viewed photos (familiarized) and 10 new photos (unfamiliarized) for 6 seconds each in one of four possible random orders. Following each photo, the computer presented a question that asked participants to rate how much they liked the person displayed in the photo. Participants rated the degree of liking $(1=$ not at all, $9=$ very much $)$ and then pressed the space bar of the computer keyboard to view the next photo. Following the experiment, participants were questioned and told of the purpose of the research. During questioning, no participants guessed any of the hypotheses or suspected that the first study was related to the second study.

\section{Assessment of EMG and EEG}

EEG was recorded over left and right frontal and parietal regions during the resting baseline session and during the viewing of each picture as it was presented in the test phase. More specifically, EEG was recorded with tin electrodes in a stretch-lycra cap (Electro-Cap Inter- 
national, Inc., Eaton, Ohio) at sites F3, F4, P3, and P4, referenced to $\mathrm{Cz}$ (sites from the International 10-20) (Jasper, 1958), after reducing electrode impedances to less than 5 Kohms. Signals were amplified by a factor of 20,000 with AC differential amplifiers (bandpass 0.1 and $100 \mathrm{~Hz}$ ) and digitized continuously at $2048 \mathrm{~Hz}$. To monitor eye movements, tin electrodes were affixed to the outer canthus and superior orbit (amplification $=5 \mathrm{~K}$, bandpass $=0.1$ to $100 \mathrm{~Hz}$ ) .

Facial EMG was recorded during the resting baseline session and during the viewing of each picture as it was presented in the test phase. Facial EMG was recorded with miniature $\mathrm{Ag} / \mathrm{Ag}-\mathrm{Cl}$ electrodes filled with Redux Paste attached bilaterally in pairs over the corrugator supercilii (brow) and zygomaticus major (cheek) muscle regions using the guidelines for EMG placements suggested by Fridlund and Cacioppo (1986). Attachment of electrodes was made after the interelectrode impedances were reduced to less than $10 \mathrm{Kohms.} \mathrm{EMG} \mathrm{signals}$ were recorded in a bipolar fashion (with two adjacent electrodes over the same muscle region referenced to one another), amplified by a factor of 20,000 with AC differential amplifiers (bandpass 0.1 and $1,000 \mathrm{~Hz}$ ) and digitized continuously at $2048 \mathrm{~Hz}$.

\section{Data Analyses}

EEG analyses. Frontal asymmetries in alpha activity during the baseline eyes-open period (Tomarken et al., 1990) and during picture viewing were computed. Parietal asymmetries were also computed to test whether predicted relations of frontal asymmetry to responses to merely exposed stimuli were localized to frontal regions or were due to generalized cerebral lateralization not specific to the frontal regions. EEG was first visually inspected for movement and muscle artifacts on a highresolution computer monitor. Data that contained artifacts were removed from the record, such that artifacts in one channel caused removal of all channels at that point in time. Data were then epoched into 2-second epochs, overlapping by $75 \%$. The power spectra were derived via the fast Fourier transform (FFT) method using a Hamming window with tapering $10 \%$ of the distance from each end of the epoch for each 2-second epoch and then averaged for each participant to produce the total power in the alpha $(8-13 \mathrm{~Hz})$ band. Frontal and parietal asymmetry indexes (base $10 \mathrm{log}$ right minus base $10 \mathrm{log}$ left alpha power) were computed (Tomarken et al., 1992). Because alpha power is inversely related to activation (Davidson, 1988), higher scores on the index indicate greater left hemisphere activation.

EMG analysis. EMG was screened for movement artifacts through visual inspection on a high-resolution computer monitor, then high-pass filtered (1/2 amplitude frequency $=10 \mathrm{~Hz}$ ) and rectified off-line. ${ }^{2}$ Our method for integrating/smoothing involved taking the average of the filtered-rectified activity. This method smoothed by a simple unweighted average across each epoch (1 second).

EEG and EMG during picture viewing. An examination of the raw data revealed that the first second of picture viewing contained much eye movement and muscle artifact (similar problems occurred in Greenwald, Cook, \& Lang, 1989). Thus, analyses were performed on the EEG and EMG activity that occurred in seconds 2 through 6 of picture viewing. Because no meaningful effects involving time block occurred, the data were averaged across seconds 2 through 6 , and time block was not used as a factor in the reported analyses. In addition, preliminary analyses revealed no significant laterality effects involving the right-left factor of facial EMG, so data were collapsed across left and right sides and this factor was not included in the reported analyses. EEG, EMG, and reported liking responses were averaged across novel and familiarized stimuli.

\section{RESULTS}

\section{Results Across All Participants}

Replicating past research, familiar pictures $(M=6.18$, $S D=1.00)$ were rated as more likeable than unfamiliar pictures $(M=5.98, S D=1.17), t(32)=2.20, p=.035, r=.36$.

Extending past research, more zygomatic muscle region activity occurred during the viewing of the familiar pictures $(M=2.45$ microvolts, $S D=1.23)$ than during the viewing of the unfamiliar pictures $(M=2.27, S D=$ 1.22), $t(30)=2.07, p=.05, r=.35$. The difference in zygomatic activity between familiar and unfamiliar stimuli indicated increased zygomatic activity to the familiar rather than decreased zygomatic activity to the unfamiliar, as zygomatic activity increased marginally from resting baseline $(M=2.19, S D=1.30)$ to viewing of the familiar, $t(30)=1.66, p=.11, r=.29$, but did not decrease from baseline to viewing of the unfamiliar, $p>.30$. No significant differences emerged as a function of mere exposure for corrugator muscle region activity, frontal cortical asymmetry, or parietal cortical asymmetry, $p s>.23$. These results support the hypothesis that zygomatic muscle region activity would be greater for familiar than for unfamiliar stimuli. These results, however, do not support the hypotheses that corrugator muscle region activity and that relative right frontal cortical activity would be greater for unfamiliar than for familiar stimuli. The EMG results for the zygomaticus muscle region demonstrate that mere exposure influences affective responses to stimuli. 


\section{Individual Differences}

We then examined whether individual differences were related to the variables that were affected by the manipulation of familiarity-facial EMG and selfreported liking responses. These individual difference variables were collected prior to the exposure phase (i.e., at baseline). The variables were self-reported positive affect, self-reported negative affect, and resting frontal cortical asymmetry. To avoid problems associated with difference scores (e.g., Keppel \& Zedeck, 1989), we first performed a regression analysis in which responses to familiarized stimuli were predicted by responses to novel stimuli-for each of the dependent measures (corrugator EMG, zygomatic EMG, liking) - and saved the standardized residuals. These residuals were then related to each of the individual differences measures to test the hypothesis that individual differences in affective and motivational dispositions would relate to differential responsivity to novel as compared with familiarized stimuli. $^{3}$

Positive affect. Persons with low reported positive affect at baseline were more likely than persons with high positive affect to evidence more zygomatic activity to the familiar than to the novel. This is revealed by the correlation between baseline positive affect and the zygomatic index, $r(29)=-.42, p=.02$, and it supports the hypothesis that persons with low positive affect would be more likely than persons with high positive affect to evidence greater zygomatic activity to the familiar as compared with the novel. No other variables related significantly with individual differences in positive affect. Correlations are displayed in Table 1.

Negative affect. Persons with high reported negative affect at baseline were more likely than persons with low negative affect to evidence more zygomatic activity to the familiar than to the unfamiliar. This effect is revealed by the correlation between negative affect and the zygomatic index, $r(29)=.44, p=.01$, and it supports the hypothesis that persons with high negative affect would be more likely than persons with low negative affect to show greater zygomatic activity to the familiar as compared with the novel. No other variables related significantly with individual differences in negative affect. Correlations are displayed in Table 1 . Consistent with the models and evidence suggesting the independence of positive and negative affect (e.g., Watson et al., 1988), in the present experiment, positive and negative affect were not significantly correlated, as displayed in Table 1.

Frontal asymmetry in cortical activity. Because relatively greater left frontal activity is characteristic of persons with increased approach motivational tendencies (Harmon-Jones \& Allen, 1997; Sutton \& Davidson,
TABLE 1: Correlations Between Variables

\begin{tabular}{lccccccc}
\hline \multicolumn{7}{c}{ Positive Negative } \\
& $\mathrm{M}$ & (SD) & Affect & Affect Asymm B & Corr & Zygo & Liking \\
\hline Positive & & & & & \\
$\quad$ affect & 3.14 & $(0.71)$ & & & & \\
Negative & & & & & & \\
$\quad$ affect & 1.37 & $(0.35)$ & -.25 & & & & \\
Asymm B & 0.057 & $(0.031)$ & .16 & -.02 & & & \\
Corr & -0.04 & $(0.55)$ & .07 & -.03 & .19 & & \\
Zygo & 0.18 & $(0.48)$ & $-.42^{* *}$ & $.44 * *$ & -.02 & .16 & \\
Liking & 0.20 & $(0.52)$ & -.23 & .23 & $-.29 *$ & .10 & $.41^{* *}$ \\
Asymm P & -0.008 & $(0.039)-.10$ & -.03 & .01 & -.19 & $-.41^{* *}-.01$ \\
\hline
\end{tabular}

NOTE: Positive affect $=$ positive affect at baseline; negative affect $=$ negative affect at baseline; Asymm B = frontal asymmetry in alpha power at baseline (greater scores are associated with relatively greater left than right activation); corr = corrugator muscle region (brow) activity to familiar as compared with novel stimuli; zygo = zygomatic muscle region (cheek) activity to familiar as compared with novel stimuli; liking = reported liking of familiar as compared with novel stimuli; Asymm P = frontal asymmetry in alpha power to familiar as compared with novel stimuli. Corr, zygo, Liking, and Asymm $\mathrm{P}$ were created using residual scores (see Results section). Means and standard deviations for corr, zygo, liking, and Asymm $\mathrm{P}$ are expressed in difference scores (response to familiar minus response to novel stimuli).

$* p<.11 . * * p<.05$.

1997), we examined the relation of resting frontal asymmetry with EMG and liking responses. A marginally significant relation occurred between resting frontal asymmetry and reported liking of the stimuli, which indicated that greater left-than-right frontal activity was associated with decreased liking for familiarized as compared with novel stimuli, $r(30)=-.29, p=.11$.

In addition to the above correlational approach, participants were classified as low or high in approach motivation on the basis of their resting frontal cortical asymmetry. This was done because previous research has suggested that the resting anterior asymmetry may be more appropriately treated as a discrete variable rather than as a continuous one (Tomarken et al., 1992). Participants classified as low in approach motivation were more likely than persons classified as high in approach motivation to rate the familiar as more likeable than the unfamiliar. When participants in the upper and lower quartiles of resting frontal EEG asymmetry scores were examined, a marginally significant frontal asymmetry group (upper vs. low quartile) by familiarity (familiar vs. unfamiliar) interaction emerged, $F(1,14)=3.89, p<.07$, $r=.46$. The interaction revealed that persons with relatively less left-sided activity rated the familiar as more likable $(M=6.40, S D=1.34)$ than the unfamiliar $(M=5.80$, $S D=1.66), t(14)=3.35, p<.01, r=.67$, and that persons with relatively more left-sided activity $\operatorname{did}$ not $(M s=5.90$ and 5.80, $S D$ s $=1.17$ and 1.00$), t(14)=0.56, p>.50, r=$ .15. These results suggest that persons with frontal corti- 
cal activation reflecting a lower approach-related affective style prefer the familiar over the unfamiliar more than do persons with a heightened approach-related affective style. No significant effects of frontal asymmetry on EMG or EEG responses to the stimuli resulted. No significant relations were observed for resting parietal asymmetry and EMG, EEG, or liking responses to the stimuli $(r \mathrm{~s}<.10)$, thus establishing the regional specificity of the effect. ${ }^{4}$

\section{Correlational Analyses}

As can be seen in Table 1, the zygomatic index correlated significantly with the liking index, suggesting that the more participants evidenced increased zygomatic muscle region activity to familiar as compared with novel stimuli, the more they reported increased liking for familiar as compared with novel stimuli.

Unexpectedly, the zygomatic index correlated negatively with relatively greater left frontal activity to familiar as compared with novel stimuli (i.e., the asymmetry index), suggesting that positive affect was associated with decreased approach motivation to these stimuli. Before accepting this interpretation, however, it is important to consider some aspects of the data. First, an examination of the variables revealed that one participant was more than 3.5 standard deviations from the mean on the asymmetry index. With this participant removed from the analyses, the relationship of the zygomatic index with the asymmetry index was not significant $(r=-.23, p>$ .20). In addition, removal of this participant from the other analyses did not decrease the significance levels of any of the reported effects. Second, the corrugator index also correlated negatively (although not as strongly) with the asymmetry index, indicating that any relationship of asymmetrical frontal activity with facial muscle activity was not entirely restricted to positive affect. Third, the asymmetry index did not correlate with other critical variables or differ as a function of familiarity. After observing the unexpected correlation between the asymmetry index and the zygomatic index, we were concerned whether it would account for the relationship between the zygomatic index and the liking index. To examine this issue, we conducted a partial correlation analysis in which the effects of the asymmetry index on the relationship between the zygomatic index and liking were controlled. The partial correlation of the zygomatic index and liking remained significant, in an analysis with all participants and in an analysis with the aforementioned outlier removed (both partial $r \mathrm{~s}=.45, p<.02$ ).

\section{DISCUSSION}

The results are consistent with the hypothesis that mere exposure evokes positive affective responses. In addition to participants rating familiar stimuli as more likable than unfamiliar stimuli, they evidenced more zygomatic muscle region activity while viewing familiar as compared with unfamiliar stimuli. Participants did not evidence more corrugator muscle region activity to the unfamiliar than to the familiar, as would be hypothesized by affective explanations of the mere exposure effect. Because zygomatic muscle region activity increased in response to the familiar and did not decrease in response to the unfamiliar and because corrugator muscle region activity was not affected by mere exposure, this research more strongly supports the hypothesis that mere exposure enhances positive affect toward familiarized stimuli than the hypothesis that mere exposure decreases negative affect toward familiarized stimuli.

The results are consistent with predictions derived from affective models of mere exposure in that the present results show that mere exposure affects emotional responses. However, these past models considered positive and negative affect to be reciprocally activated rather than independently activated, suggesting that mere exposure should increase positive affect as well as decrease negative affect. The present results provide stronger support for the idea that mere exposure increases positive affect toward stimuli than for the idea that mere exposure decreases negative affect. These effects are not specifically predicted by the past affective mere exposure theories. However, it would be premature to conclude that mere exposure will never decrease negative affect. For instance, research with nonhuman animals suggests that they will respond to novel stimuli with distress and that the distress is reduced with mere exposure (e.g., Zajonc, Markus, \& Wilson, 1974b). Thus, explanations for the mere exposure effect need to consider the idea that the type of stimulus may independently moderate positive and negative responses (see Cacioppo \& Berntson, 1994, for a discussion of the independence of positive and negative responses). It is important to note that in the present experiment, photographs of other persons were used as stimuli. Similar social stimuli have been used in several mere exposure studies, and robust effects have been observed using these stimuli.

Asymmetrical frontal cortical activity during the viewing of the stimuli did not differ as a function of familiarity. Although past research has suggested that state manipulations of emotions affect asymmetrical frontal activity (Davidson, Ekman, Saron, Senulis, \& Friesen, 1990; Ekman \& Davidson, 1993), it is important to note that in this past research, relatively strong manipulations of emotion were used, and even with these strong manipulations, the effects of emotion on asymmetrical activity 
were most often observed only during periods of time in which facial expressions of emotion, which were perceptible to other persons, were produced. The effects of mere exposure on emotion were probably not sufficient to produce large emotional responses and visually perceptible facial expressions of emotions. Along these lines, past research has demonstrated that changes in EMG are not necessarily socially perceptible (e.g., Cacioppo, Martzke, Petty, \& Tassinary, 1988). As with all null effects, other explanations exist for the lack of a difference.

\section{The Association of EMG and Reported Liking}

Increased zygomatic muscle region activity to the merely exposed stimuli was associated with increased liking for these stimuli. Whether the increased zygomatic activity led to the increased liking or vice versa cannot be determined from this experiment. It is also plausible that the liking measure and the zygomatic measure are measures of the same affective construct and thus bear no causal relation to one another. In addition, other variables may moderate the relationship between zygomatic activity and liking, such as the extent to which individuals process the merely exposed stimuli in a rational (cognition-oriented) as compared with experiential (feelings-oriented) mode (Epstein, Pacini, Denes-Raj, \& Heier, 1996; Simon et al., 1997).

\section{Individual Differences in \\ Responses to Mere Exposure}

In addition to examining the effects of mere exposure on affective reactions to stimuli, this research examined potential individual difference moderators of the evaluative and psychophysiological responses to familiarized and unfamiliarized stimuli. The individual differences examined offered insight into potential moderators of the mere exposure effect. Persons with more selfreported negative affect at baseline and persons with less self-reported positive affect at baseline evidenced more zygomatic muscle region activity to the familiar than to the unfamiliar, whereas persons with less negative affect and persons with more positive affect did not. It should be noted, however, that individual differences in frontal cortical activity did not relate to EMG responses. However, persons with asymmetrical frontal cortical activity reflecting a lower approach-related affective style demonstrated a marginally significant tendency to evaluate the familiar as more likable than the unfamiliar, whereas persons with asymmetrical frontal cortical activity reflecting a greater approach-related affective style did not. Taken together, these results, which suggest that the mere exposure effect is moderated by individual differ- ences in affective styles, are consistent with affective explanations of mere exposure.

\section{Limitations and Future \\ Research Directions}

This research supports the idea that affect is involved in the mere exposure effect and suggests, along with other recent research, that the nonspecific activation and perceptual fluency/attribution models cannot adequately explain the mere exposure effect (Reber et al., 1998; Seamon et al., 1998). Although this research offers support for an affective explanation of mere exposure, it is not able to distinguish an affective model explanation from the affective-perceptual fluency model explanation. The effects on positive affect caused by mere exposure may have resulted from increased ease of processing, as suggested by the affective-perceptual fluency model, or by a mechanism suggested by one of the affective models. Future research will be necessary to distinguish these explanations, and such research would need to operationalize real-time measures not only of affect, as in this study, but of perceptual fluency as well. The important contribution of this research is that mere exposure does indeed influence affective states and that individual differences in affective style moderate these affective responses.

In addition, it should be noted that the effects obtained in this research were small to medium in size. However, as has been argued, small effects can be quite important (Abelson, 1985). The small effects obtained are potentially important because they occurred following a minimal manipulation and had effects on subjective experience and facial efference. In addition, the observed effects address important theoretical issues.

Finally, this experiment included only two levels of exposure: five presentations or no presentations (as in, e.g., Bornstein et al., 1987; Kunst-Wilson \& Zajonc, 1980). We decided not to include multiple levels of exposure because it would have substantially increased the time of the experiment, which may have caused a reduction in the viewing of the stimuli and may have led to more movement artifacts in the EMG and EEG data. ${ }^{5}$ Future studies could extend the present research by including multiple levels of exposure to assess whether the effects of mere exposure on zygomatic region activity at higher levels of exposure are reduced (i.e., an inverted U-shaped relationship between frequency of exposure and affective response; e.g., Bornstein, 1989; Zajonc, Crandall, Kail, \& Swap, 1974).

\section{CONCLUSION}

This research addressed a question central to many of the explanations of the mere exposure effect by demon- 
strating that mere exposure evokes increased positive affect, as measured by facial EMG. These results extend past research by demonstrating that mere exposure affects facial efference. The present research supported the assumptions of affective models of mere exposure by demonstrating that simply exposing persons to nonreinforced stimuli repeatedly increased their positive affective reactions toward these stimuli. In addition, the research demonstrated that these affective responses were moderated by individual differences in affective style.

\section{NOTES}

1. The evolutionary model is also consistent with results indicating that mere exposure effects are stronger in adults than in small children. According to this model, for organisms under the care of another (i.e., children), the expression of a mere exposure effect is not as necessary for survival.

2. Although rectification should ensure that all electromyographic (EMG) data points are positive numbers, the Neuroscan data analysis package stores a baseline correction value in the header of the data file that it continues to apply after rectification. Although the use of such a baseline value is sensible for typical AC signals, the introduction of such a baseline offset after rectification would introduce error. Therefore, when using the Neuroscan system to analyze EMG data, all baseline values must be set to zero following rectification.

3. Results computed with difference scores yielded identical results.

4. Participants scored in the upper or lower third of the distribution of 152 social anxiety scores (on the Social Anxiety and Distress Scale of Watson \& Friend, 1969). No effects involving social anxiety were significant. When the effects of social anxiety were partialed out of the relation between the other individual difference variables and responses to familiarized versus unfamiliarized stimuli using partial correlational analyses, the partial correlation of the other individual difference variables and responses to familiarized versus unfamiliarized stimuli remained significant and approximately the same as the zero-order correlations.

5. When the test phase began, participants had already been sitting in the chair wearing electrodes for approximately 80 minutes (e.g., 50 minutes for introduction, consent form, and electrode attachment; 8 minutes for resting baseline; 15 minutes for completion of the PANAS and the SAD; 2 minutes for exposure phase; 5-minute delay between exposure and test phase). It is also possible that an increase in the duration of the experiment would have increased boredom and that this increase in boredom might have attenuated the mere exposure effect, because Bornstein, Kale, and Cornell (1990) found that individuals high in boredom proneness evidenced a reduced mere exposure effect. An increase in boredom might reduce the size of the mere exposure effect because boredom reduces the potential for the experience of positive affect to the merely exposed stimuli.

\section{REFERENCES}

Abelson, R. P. (1985). A variance explanation paradox: When a little is a lot. Psychological Bulletin, 103, 193-210.

Bornstein, R. F. (1989). Exposure and affect: Overview and metaanalysis of research, 1968-1987. Psychological Bulletin, 106, 265-289.

Bornstein, R. F. (1992). Subliminal mere exposure effects. In R. F. Bornstein \& T. S. Pittman (Eds.), Perception without awareness (pp. 191-210). New York: Guilford.

Bornstein, R. F., \& D'Agostino, P. R. (1992). Stimulus recognition and the mere exposure effect. Journal of Personality and Social Psychology, 63, 545-552.

Bornstein, R. F., \& D'Agostino, P. R. (1994). The attribution and discounting of perceptual fluency: Preliminary tests of a perceptual fluency/attributional model of the mere exposure effect. Social Cognition, 12, 103-128.

Bornstein, R. F., Kale, A. R., \& Cornell, K. R. (1990). Boredom as a limiting condition on the mere exposure effect. Journal of Personality and Social Psychology, 58, 791-800.

Bornstein, R. F., Leone, D. R., \& Galley, D. J. (1987). The generalizability of subliminal mere exposure effects: Influence of stimuli perceived without awareness on social behavior. Journal of Personality and Social Psychology, 53, 1070-1079.

Bowlby, J. (1958). The nature of the child's tie to his mother. International Journal of Psychoanalysis, 39, 350-373.

Bronson, G. W. (1968). The fear of novelty. Psychological Bulletin, 69, 350-358.

Cacioppo, J. T., \& Berntson, G. G. (1994). Relationship between attitudes and evaluative space: A critical review, with emphasis on the separability of positive and negative substrates. Psychological Bulletin, 115, 401-423.

Cacioppo, J. T., Martzke, J. S., Petty, R. E., \& Tassinary, L. G. (1988). Specific forms of facial EMG response index emotions during an interview: From Darwin to the continuous flow hypothesis of affect-laden information processing. Journal of Personality and Social Psychology, 54, 592-604.

Cacioppo, J. T., Tassinary, L. G., \& Fridlund, A. J. (1990). The skeletomotor system. In J. T. Cacioppo \& L. G. Tassinary (Eds.), Principles of psychophysiology: Physical, social, and inferential elements (pp. 325-384). New York: Cambridge.

Chapman, L. J., \& Chapman, J. P. (1987). The measurement of handedness. Brain and Cognition, 6, 175-183.

Crandall. (1968). Effects of need for approval and intolerance of ambiguity upon stimulus preference. Journal of Personality, 36, 67-83.

Davidson, R. J. (1988). EEG measures of cerebral asymmetry: Conceptual and methodological issues. International Journal of Neuroscience, 39, 71-89.

Davidson, R. J. (1995). Cerebral asymmetry, emotion, and affective style. In R. J. Davidson \& K. Hugdahl (Eds.), Brain asymmetry (pp. 361-387). Cambridge: Massachusetts Institute of Technology.

Davidson, R. J., Ekman, P., Saron, C. D., Senulis, J. A., \& Friesen, W. V. (1990). Approach-withdrawal and cerebral asymmetry: Emotional expression and brain physiology I. Journal of Personality and Social Psychology, 58, 330-341.

Dimberg, U. (1990). Facial electromyography and emotional reactions. Psychophysiology, 27, 481-494.

Ekman, P., \& Davidson, R. J. (1993). Voluntary smiling changes regional brain activity. Psychological Science, 4, 342-345.

Epstein, S., Pacini, R., Denes-Raj, V., \& Heier, H. (1996). Individual differences in intuitive-experiential and analytical-rational thinking styles. Journal of Personality and Social Psychology, 71, 390-405.

Fechner, G. T. (1876). Vorschule der Aesthetik. Leipzig, Germany: Breitkopf and Härtel.

Fridlund, A. J., \& Cacioppo, J. T. (1986). Guidelines for human electromyographic research. Psychophysiology, 23, 567-589.

Greenwald, M. K., Cook, E. W. III, \& Lang, P. J. (1989). Affective judgment and psychophysiological response: Dimensional covariation in the evaluation of pictorial stimuli. Journal of Psychophysiology, 3, $51-64$.

Harmon-Jones, E., \& Allen, J. J. B. (1997). Behavioral activation sensitivity and resting frontal EEG asymmetry: Covariation of putative indicators related to risk for mood disorders. Journal of Abnormal Psychology, 106, 159-163.

Harmon-Jones, E., \& Allen, J. J. B. (1998). Anger and prefrontal brain activity: EEG asymmetry consistent with approach motivation despite negative affective valence. Journal of Personality and Social Psychology, 74, 1310-1316.

Harrison, A. A. (1977). Mere exposure. In L. Berkowitz (Ed.), Advances in experimental social psychology (Vol. 10, pp. 39-83). New York: Academic Press.

Hill, W. F. (1978). Effects of mere exposure on preferences in nonhuman animals. Psychological Bulletin, 85, 1177-1198.

Jacoby, L. L., \& Whitehouse, K. (1989). An illusion of memory: False recognition influenced by unconscious perception. Journal of Experimental Psychology: General, 118, 126-135. 
James, W. (1890). The principles of psychology (Vol. 2). New York: Holt.

Jasper, H. (1958). Report on the committee on methods of clinical examination in electroencephalography. Electroencephalography and Clinical Neurophysiology, 10, 370-375.

Keppel, G., \& Zedeck, S. (1989). Data analysis for research designs: Analysis of variance and multiple regression/correlation approaches. New York: W. H. Freeman.

Kunst-Wilson, W. R., \& Zajonc, R. B. (1980). Affective discrimination of stimuli that cannot be recognized. Science, 207, 557-558.

Lang, P. J., Bradley, M. M., \& Cuthbert, B. N. (1997). Motivated attention: Affect, activation, and action. In P. J. Lang, R. F. Simons, \& M. T. Balaban (Eds.), Attention and orienting: Sensory and motivational processes (pp. 97-135). Mahwah, NJ: Lawrence Erlbaum.

Mandler, G., Nakamura, Y., \& Van Zandt, B. J. (1987). Nonspecific effects of exposure on stimuli that cannot be recognized. Journal of Experimental Psychology: Learning, Memory, and Cognition, 13, 646648.

Maslow, A. H. (1937). The influence of familiarization on preference. Journal of Experimental Psychology, 21, 162-180.

Moreland, R. L., \& Zajonc, R. B. (1976). A strong test of exposure effects. Journal of Experimental Social Psychology, 12, 170-179.

Reber, R., Winkielman, P., \& Schwarz, N. (1998). Effects of perceptual fluency on affective judgments. Psychological Science, 9, 45-48.

Saegert, S. C., Swap, W. C., \& Zajonc, R. B. (1973). Exposure, context, and interpersonal attraction. Journal of Personality and Social Psychology, 25, 234-242.

Schick, C., McGlynn, R. P., \& Woolam, D. (1972). Perception of cartoon humor as a function of familiarity and anxiety level. Journal of Personality and Social Psychology, 24, 22-25.

Seamon, J. G., Brody, N., \& Krauf, D. M. (1983). Affective discrimination of stimuli that are not recognized, II: Effect of delay between study and test. Bulletin of the Psychonomic Society, 9, 544-555.

Seamon, J. G., McKenna, P. A., \& Binder, N. (1998). The mere exposure effect is differentially sensitive to different judgment tasks. Consciousness and Cognition, 7, 85-102.

Simon, L., Greenberg, J., Harmon-Jones, E., Solomon, S., Pyszczynski, T., \& Abend, T. (1997). Terror management and cognitive experiential self theory: Evidence that terror management occurs in the experiential system. Journal of Personality and Social Psychology, 72, 1132-1146.
Sutton, S. K., \& Davidson, R. J. (1997). Prefrontal brain asymmetry: A biological substrate of the behavioral approach and inhibition systems. Psychological Science, 8, 204-210.

Tomarken, A. J., Davidson, R. J., \& Henriques, J. B. (1990). Resting frontal brain asymmetry predicts affective responses to films. Journal of Personality and Social Psychology, 59, 791-801.

Tomarken, A. J., Davidson, R. J., Wheeler, R. E., \& Kinney, L. (1992). Psychometric properties of resting anterior EEG asymmetry: Temporal stability and internal consistency. Psychophysiology, 29, 576592.

Watson, D., Clark, L. A., \& Tellegen, A. (1988). Development and validation of brief measures of Positive and Negative Affect: The PANAS scales. Journal of Personality and Social Psychology, 54, 10631070.

Watson, D., \& Friend, R. (1969). Measurement of social-evaluative anxiety. Journal of Consulting and Clinical Psychology, 33, 448-457.

Zajonc, R. B. (1968). Attitudinal effects of mere exposure. Journal of Personality and Social Psychology Monographs, 9(2, Pt. 2), 1-27.

Zajonc, R. B. (1998). Emotions. In D. T. Gilbert, S. T. Fiske, \& G. Lindzey (Eds.), The handbook of social psychology (4th ed., pp. 591-632). Boston: McGraw-Hill.

Zajonc, R. B., Crandall, R., Kail, R. V., \& Swap, W. (1974). Effect of extreme exposure frequencies on different affective ratings of stimuli. Perceptual and Motor Skills, 38, 667-678.

Zajonc, R. B., Markus, H., \& Wilson, W. R. (1974a). Exposure effects and associative learning. Journal of Experimental Social Psychology, 10, 248-263.

Zajonc, R. B., Markus, H., \& Wilson, W. R. (1974b). Exposure, object preference, and distress in the domestic chick. Journal of Comparative and Physiological Psychology, 86, 581-585.

Zajonc, R. B., \& Rajecki, D. W. (1969). Exposure and affect: A field experiment. Psychonomic Science, 17, 216-217.

Zajonc, R. B., Shaver, P., Tavris, C., \& Van Kreveld, D. (1972). Exposure, satiation, and stimulus discriminability. Journal of Personality and Social Psychology, 3, 270-280.

Received March 20, 2000

Revision accepted July 19, 2000 